\title{
Identifying Judicial Empathy: Does Having Daughters Cause Judges to Rule for Women's Issues?
}

\author{
Adam N. Glynn Emory University \\ Maya Sen Harvard University
}

\begin{abstract}
In this article, we consider whether personal relationships can affect the way that judges decide cases. To do so, we leverage the natural experiment of a child's gender to identify the effect of having daughters on the votes of judges. Using new data on the family lives of U.S. Courts of Appeals judges, we find that, conditional on the number of children a judge has, judges with daughters consistently vote in a more feminist fashion on gender issues than judges who have only sons. This result survives a number of robustness tests and appears to be driven primarily by Republican judges. More broadly, this result demonstrates that personal experiences influence how judges make decisions, and this is the first article to show that empathy may indeed be a component in how judges decide cases.
\end{abstract}

We need somebody who's got the heart, the empathy, to recognize what it's like to be a young teenage mom. The empathy to understand what it's like to be poor, or African-American, or gay, or disabled, or old. And that's the criteria by which I'm going to be selecting my judges.

—Barack Obama, on a 2007 campaign stop

U pon Justice David Souter's retirement in May 2009, President Obama made it clear that one of the criteria he would use in selecting Souter's replacement would be "empathy" - that is, a potential nominee's ability to identify "with people's hopes and struggles as an essential ingredient for arriving at just decisions and outcomes" (Obama 2009). The statement echoed much of what Obama emphasized throughout his campaign: that the ability to empathize with others is, and ought to be, a key criterion for nomination to the nation's federal courts.

Obama's press statement was among the first by a U.S. president acknowledging the possible effect of personal relationships and empathy on the way judges decide cases, and it ignited a fierce and ongoing debate. Critics have strongly questioned whether judges do (or should) have any kind of empathetic feelings that might be based on their relationships with others. As one commentator complained, relying on empathy would translate into judges "being partial instead of being impartial," when, in fact, "a judge is supposed to have empathy for no one but simply to follow the law" (Garrett 2009). Supporters, on the other hand, have applauded Obama's sense that empathy with others ought to be an important part of judicial decision making, with some commentators going as far as arguing that the "single value we should demand in a justice [has] nothing to do with race or gender," but "everything to do with empathy for others" (Lithwick and West 2010). So divisive has been this debate that discussions about empathy largely dominated coverage of Sonia Sotomayor's and Elena Kagan's Supreme Court nominations, leading one news organization to label the attendant vitriol as the "Empathy Wars" (Just 2009).

While the public debate has been framed around empathy, critics have been more broadly concerned with whether personal relationships affect decisions in any

Adam Glynn is Associate Professor, Department of Political Science, Emory University, 327 Tarbutton Hall, 1555 Dickey Drive, Atlanta, GA 30322 (aglynn@emory.edu). Maya Sen is Assistant Professor, Harvard Kennedy School, 79 John F. Kennedy Street, Cambridge, MA 02138 (maya_sen@hks.harvard.edu).

We thank Matthew Blackwell, Tom Clark, David Gelman, Jennifer Hochschild, Gary King, Jeff Lax, and Kevin Quinn for helpful comments and suggestions. We are also grateful to seminar or conference participants at the Harvard Department of Government, the Harvard Kennedy School, Duke Law School, the University of Rochester Political Science Department, and the 2011 MPSA, 2011 EPSA, and 2012 Political Economy \& Public Law meetings. Special thanks to Alex Crabill, Melissa Niedrich, and Michelle Pearse for research support. This research was supported by the Institute for Quantitative Social Science at Harvard University. Replication files are available in the AJPS Data Archive on Dataverse (http://dvn.iq.harvard.edu/dvn/dv/ajps).

American Journal of Political Science, Vol. 59, No. 1, January 2015, Pp. 37-54 
manner, via empathy or other kinds of attachments. However, there has been little theoretical or empirical work addressing the possibility that personal relationships or empathy could affect judicial decision making. Part of the problem is that untangling the causal effect of such relationships is extremely difficult. Due to homophily, people who are like-minded tend to flock together; liberals are more likely to associate with liberals and conservatives with conservatives. Thus, determining whether personal relationships affect judicial decision making is challenging, if not impossible, under most circumstances. The judicial politics literature has therefore focused on characteristics such as partisanship (e.g., Sunstein et al. 2006) or race/gender (e.g., Boyd, Epstein, and Martin 2010; Kastellec 2013) in predicting decision making. However, this overlooks legal and historical scholarship showing that personal relationships and experiences may influence decision making. Despite the difficulties associated with quantitatively evaluating the effect of these kinds of relationships, a robust theory of judicial decision making should take these factors into account.

This article is the first to provide robust empirical support for the idea that personal relationships-as distinct from partisanship, race, or gender-may affect how judges decide cases, and this evidence cannot be explained by jurisprudence alone. We do so by focusing on one kind of personal relationship that historians and journalists have flagged as being particularly transformative: having daughters. Not only could parenting daughters cause a judge to change his or her substantive position (e.g., by becoming more progressive on gender issues), but it also avoids the homophily problem associated with other kinds of relationships. Specifically, once a couple decides to have a child, the sex of that child is outside of that couple's control, resulting in a natural quasi-experiment (Washington 2008). Employing a new data set on federal judges' families in tandem with a new data set on nearly 1,000 gender-related cases, we show that judges with at least one daughter vote in a more liberal fashion on gender issues than judges with sons, conditional on the number of children. The effect is robust and appears driven largely by Republican male appointees.

This article proceeds as follows. We begin by discussing the existing literature on personal attributes and judicial decision making, and then by theoretically linking this literature to the example of having daughters. We next discuss the data, which are data on the families of 224 judges sitting on the U.S. Courts of Appeals, as well as nearly 1,000 gender-related cases decided by these judges. (Additional information on how the data were collected is presented in the online supporting information.) We then present our main findings, which show that judges who have girls as opposed to boys are more likely to vote in a liberal direction on these cases. We discuss the evidence for and against competing explanations of our findings and conclude by emphasizing the implications of this research on the existing debate about empathy and judicial actors as well as on the literature on judicial decision making.

\section{How Relationships Could Affect Decision Making}

We start by considering the role that personal relationships might play in judicial politics. Relatively little scholarly attention has focused on the issue, probably due to the difficulty of estimating the causal impact of relationships that have been sought out voluntarily. Thus, the bulk of the literature in judicial politics has been devoted to ascertaining the impact of personal characteristics (as opposed to personal relationships or experiences) on judicial decision making. A substantial literature in this vein therefore documents the important role of partisanship in how judges decide cases (e.g., Howard and Segal 2002; Rohde and Spaeth 1976; Schubert 1974; Segal and Spaeth 2002; Sunstein et al. 2006). This includes findings that Democratic appointees are more likely than Republican appointees to reach liberal decisions (e.g., Segal and Spaeth 2002; Sunstein et al. 2006) or that a Democrat sitting with two Republican colleagues on a three-judge appeals panel may pull those Republicans toward a more liberal ruling (Sunstein et al. 2006).

More recent scholarship has enriched this understanding by exploring additional characteristics such as race and gender. For example, Boyd, Epstein, and Martin (2010) demonstrate that female judges vote differently than male judges, but only in instances involving sex discrimination. ${ }^{1}$ Other literature has found that being a female judge has an effect on cases involving sexual harassment, sex discrimination, or the sentences of criminal defendants (e.g., Baldez, Epstein, and Martin 2006; Davis, Haire, and Songer 1993; Massie, Johnson, and Gubala 2002; Peresie 2005; Segal and Spaeth 2002). A companion body of literature has found differences between judges of different races, for example, showing that African American judges are more likely to rule liberally on cases having a substantive racial

\footnotetext{
${ }^{1}$ In addition to these findings on individual effects, Boyd, Epstein, and Martin (2010) also present findings on panel effects (i.e., the effect of one member of a panel on another). These panel effects findings are not directly relevant for the results discussed in this article.
} 
dimension (see, e.g., Cox and Miles 2008; Gottschall 1983; Kastellec 2013; Scherer 2004). Taken together, this literature suggests that a robust theory of judicial politics must incorporate not only partisanship and strategic interactions, but also identity.

Despite this scholarship, numerous historians, legal scholars, and journalists have noted that many judges reach decisions that their partisan or demographic leanings fail to predict (Greenhouse 2003; Toobin 2007). For example, Justice William Rehnquist, a leading proponent of states' rights, ruled that states would have to abide by the Family and Medical Leave Act; speculation was rampant that his experience watching his divorced daughter, Janet, juggle family life affected his views (Greenhouse 2003; Novak 2003). Another example is Justice Harry Blackmun, whose college-aged daughter became pregnant, dropped out of university, and had a miscarriage, all in the six years before he would go on to write the opinion decriminalizing abortions in Roe v. Wade (Greenhouse 2006). These are not idiosyncrasies; in many instances, personal experiences and relationships are thought to influence how judges rule, thus invigorating a normative and political debate about the role of empathy in decision making (Colby 2012).

In terms of the scholarly literature, some studies have looked at the role that experiences, as opposed to personal characteristics (e.g., gender), may have on judicial decision making. However, most of these have looked at purely professional experiences (Epstein, Knight, and Martin 2003), and most of these have done so within the criminal sentencing context (Sisk, Heise, and Morriss 1998). Very few studies have looked at personal experiences, and, to our knowledge, no empirical inquiry has ever examined the potential effect that close or familial relationships-that is, those relationships that might be most pivotal-might have on judicial decision making. Thus, despite their possible importance, personal relationships have yet to be fully incorporated into a theory of judicial decision making.

\section{Focusing on the Relationship with Daughters}

This gap in the literature leads us to our core inquiry: whether we can identify the effects of personal experiences on decision making. In exploring this question, we address whether these kinds of personal relationships could possibly be on par with other attributes that drive how judges behave. If so, then personal experiences and relationships perhaps should be considered alongside par- tisanship and demographic characteristics in the components that determine our theoretical understanding of judicial decision making.

In this analysis, we focus on only one kind of personal experience: having daughters. Although other relationships may be equally important, we focus on daughters for two reasons. First, we know from journalistic accounts that these kinds of experiences likely affected the justices' thinking on some major legal issues, thus providing a fruitful test for a theory incorporating personal relationships into judicial decision making; here, Justices Rehnquist and Blackmun provide two prominent examples. Second, examining the effect of daughters allows us to avoid the methodological problem of homophily. We avoid this problem by examining the effect of having daughters only after conditioning on the number of children a judge has, following the methodology of Washington (2008). Conditional on having a child, the sex of the child is analogous to a natural experiment; once a couple decides to have a child, the sex of that child is effectively outside of that couple's control and will therefore be unrelated to other individual characteristics, including partisanship or ideology. Thus, once they have decided to have a child, judges cannot choose to be a parent to a girl or boy; this relationship is established exogenously, and allows us to quantify the causal effect of a personal relationship on decision making. ${ }^{2}$

Why should having daughters affect judicial decision making? Although no literature within judicial politics has explored the issue, public opinion scholarship provides some evidence. Most of this literature suggests

${ }^{2}$ Like Washington (2008) and Iacus, King, and Porro (2011), we assume that the likelihood of a child being born a boy or a girl is out of the parents' control and unrelated to pertinent decisionmaking characteristics. The possibility does exist, however, that the probability of having a girl will vary between judges according to specific traits. For example, perhaps more conservative people are predisposed to have more boys, or more progressive or liberal people have more girls. Although no study to our knowledge has made these sorts of ideological claims, some studies have claimed that more physically attractive people have more daughters (Kanazawa 2007) and that taller and heavier people (Kanazawa 2005), battered women (Kanazawa 2008), and violent men (Kanazawa 2006) have a higher share of sons. We note that this literature is contested (see, e.g., Gelman, and Weakliem [2009] and Denny [2008] for rebuttals) and that, with the exception of violent tendencies, it is unlikely that these other traits would influence judicial decision making. This does, however, mean that the research design fails more generally when it comes to other kinds of child-gender manipulations, such as the adoption of children. Parents often have strong preferences about a child's gender, and, if given a choice, may opt for adopting a girl over a boy, a boy over a girl, or one child of each gender. Chief Justice John Roberts, for example, has two adopted children, one boy and one girl. We therefore drop from this analysis any adopted children or stepchildren. In addition, we assume that judges are not having sex-selective procedures, including sex-selective abortions. 
that having daughters leads individuals to have more liberal political and social positions than those who have sons. For example, Warner (1991) finds that both men and women who have daughters are more likely to support feminist positions than those who do not. Warner and Steel (1999) similarly demonstrate that support for policies promoting gender equity increases for both men and women when they have daughters. More recently, Oswald and Powdthavee (2010) find evidence that having daughters makes British parents more "left-wing" when it comes to their politics, whereas having sons makes them more "right-wing." Shafer and Malhotra (2011) likewise provide evidence that parenting daughters as opposed to sons leads men to have less traditional views of gender roles, but it has no effect on women. In other fields, having daughters has been shown to increase the probability that parents will divorce (Bolzendahl and Myers 2004), that male investors will shift their money into stocks as opposed to bonds (Bogan 2013), and that fathers will work longer and earn more wages but not as much as they would have if they had had sons (Lundberg and Rose 2002). The exception to this literature is Conley and Rauscher (2013), which uses public opinion data and finds that a higher proportion of female children leads to more Republican identification. Although their explanation does not reconcile the differences between their finding and that of Oswald and Powdthavee (2010), they do posit that a difference between the public and political elites is that members of the public respond to having daughters by becoming more conservative, whereas political actors are selected on the basis of their families, with liberal politicians being elected in part because they have girls. ${ }^{3}$

This literature thins when it comes to elite decision making. To our knowledge, no study has looked at this issue in the context of executive decision making. Within the legislative context, the study most similar to our own is Washington (2008; replicated via matching in Iacus, King, and Porro (2011)), which found that U.S. Congress members who have daughters are more likely to vote liberally on reproductive rights issues than those who have sons. There are, however, reasons to think that congressional legislators differ from federal judges, who serve under the constraint of legal precedent. This last fact has led many commentators to assert that judges

\footnotetext{
${ }^{3}$ Another possible exception is Healy and Malhotra (2013), who find that brothers who grew up with sisters are more likely to be conservative on gender issues later in life. One reason, they posit, is that boys with sisters are conditioned early on to expect women to do more housework. We do not expect this mechanism to play a role in our analysis, however.
}

specifically should not place any import on personal relationships.

\section{Theoretical Expectations}

Taking this literature in tandem with the literature within judicial politics, we develop and evaluate four theories behind how personal relationships (e.g., having daughters) could play a key role in affecting decision making: learning, protectionism, lobbying, and preference realignment. ${ }^{4}$ The explanations we list here are not mutually exclusive, but, as we discuss below, they do lead to some observable implications.

\section{Learning}

Theories of learning and exposure (Bolzendahl and Myers 2004; Reingold and Foust 1998) imply that personal relationships have effects via learning; that is, empathy is primarily about learning about someone else's worldview. For example, many male judges may be unfamiliar with the challenges young women face when initiating sexual harassment claims or might have limited knowledge about the laws governing maternity or family medical leave. Having a daughter would increase their knowledge about these issues and push them to the left. (Greenhouse [2003] implies that this might have been the case for Justice Rehnquist. ${ }^{5}$ ) By having a daughter-and by interacting with her and her peers-judges may learn about these issues, and this additional knowledge in turn informs their opinions. ${ }^{6}$

\footnotetext{
${ }^{4}$ As in Washington (2008), another potential explanation (or, more accurately, threat to the identification strategy) is that of selection bias, or that potential judicial candidates with daughters (especially conservatives) are less likely than those with sons to pursue a career in the judiciary, thus suggesting a daughters effect when none in fact exists; although the possibility of this seems remote, we discuss the possibility below.
}

${ }^{5}$ Greenhouse (2003) notes that Rehnquist's “daughter, Janet, is a single mother who until recently held a high-pressure job and sometimes had child care problems. Several times this term, the 78-year-old Chief Justice of the United States left work early to pick up his granddaughters from school. Not evolution, but, perhaps, life."

${ }^{6}$ We note that many issues - for example, reproductive rights issues, employment discrimination on the basis of pregnancy, and so on.are issues that primarily affect young women, as opposed to older women. Thus, perhaps most learning about these issues would come from contact with younger women, such as adult daughters (versus, for male judges, their spouses). However, gender-based differences (in terms of clothing, toys, and other kinds of messages) could appear earlier in life, and so "learning" could happen with 
Such a learning theory would imply that (1) we should see the greatest effect among those who have more to learn, specifically male judges (female judges, after all, are likely to already have had intimate firsthand experience with gender issues), and (2) we should see this effect for cases having a gendered component, which represents the cases for which learning from daughters (as opposed to sons) would be the most salient. Additionally, the learning theory would imply similar effects across Democrats and Republicans; however, the effect might be easier to detect for Republicans, as many (though not all) Democrats may already have liberal positions on gender-related issues. In addition, the learning theory would imply that we should see the greatest change coming once a judge has at least one girl; on average, having additional girls would likely not significantly increase the amount of learning about gender-related issues.

\section{Protectionism}

Another possibility is that relationship effects are operationalized via wanting to prevent emotional or physical harm; that is, people want to protect those with whom they have strong personal relationships. Under this theory, parents would want to protect their daughters from possible gender-based discrimination, resulting in increased progressive views on employment or pregnancy discrimination law. But, in addition, under this theory, parents would also want to protect their daughters from possible predators, including criminal predators, and would want to foment or promote stronger connections between the daughters and the family. In this regard, a long literature has documented parental differential treatment, some of it starting at an early age (Raley and Bianchi 2006); much of this literature suggests protectionist tendencies toward daughters, such as Condry, Condry, and Pogatshnik (1983), who find that mothers respond more quickly to the sounds of a baby girl crying; Sidorowicz and Lunney (1980), who find that baby girls are held and played with differently; or Fiese and Skillman (2000), who find that girls are less likely to be told stories promoting autonomy or independence.

Under such a theory, it is possible that we would see a general liberal trend among those having daughters across many cases having a gendered component, specifically cases involving discrimination against women. (However, we might also see a conservative trend among reproductive rights or abortion cases.) Importantly, however, we

even younger daughters as well. Our results are consistent with either of these arguments. should also see an effect in criminal cases as well, with judges with daughters being more likely to uphold sentences in cases of rape and sexual assault. More broadly, we might see that judges with daughters are more likely to side against defendants in criminal cases. The observable implication of this theory would be differences across different kinds of legal issue areas, with judges with daughters voting more liberally on civil cases having a gender component but more conservatively on criminal cases (specifically, rape and sexual assault). We also expect to see this kind of mechanism at work both for male and female judges and across party lines, with the caveat that the effect would be easier to detect for Republican judges in gender-related civil cases and among Democrats in criminal cases.

\section{Lobbying or Preference Realignment}

A slightly different take on "empathy" is that judges incur costs associated with holding views antithetical to the views of close family members because they are scolded or otherwise socially penalized at home.

For example, one possibility is that costs accrue due to social pressure or lobbying. As an illustration, we know that Justice Blackmun and his three daughters frequently discussed politics at the dinner table, and that his daughters made their progressive views well known (Greenhouse 2006). Thus, Blackmun might have incurred social costs at home if he had not voted in a liberal direction on important cases before the Court (although this is speculative). The observable implications of such a lobbying mechanism are complex, however. If all daughters are more liberal than their parents and any sons, ${ }^{7}$ daughters would lobby their parents leftward, but they might do so across all issues, not just issues having a particular gendered dimension. Thus, we might expect to see an effect of having girls across all issue areas: gender and sex discrimination, First Amendment, crime, etc. We would also see this across male and female judges as well as across party lines (although, again, the effect would be difficult to detect for Democrats). Lastly, we may also see an increasing effect with each girl, as each additional daughter applies additional pressure. ${ }^{8}$

\footnotetext{
${ }^{7}$ This is hardly a valid assumption; as scholarship from public opinion suggests, partisanship can be thought of as being transferred from parent to child (Campbell et al. 1966; Zuckerman, Dasović, and Fitzgerald 2007). We would therefore expect that children of judges roughly share the same partisanship as their parents and also their siblings.

${ }^{8}$ The observational implications become more complex (and perhaps impossible to detect) when we more realistically consider that some daughters might be more conservative than their parents and
} 
Another possibility is that costs accrue not necessarily through lobbying, but through other pathways (Bolzendahl and Myers 2004; Coltrane 1997; Gerson 1993; Kane and Sanchez 1994; Washington 2008). For example, Warner (1991) finds that those with girls (as opposed to boys) are more likely to support feminist policies-including policies promoting workplace egalitarianism. Consistent with this idea, parents with daughters might have a pecuniary interest in seeing employment discrimination against their daughters be outlawed. This kind of preference realignment would predict that judges who have daughters will take a more liberal stance on civil issues having a gendered component. However, we should expect to see this effect across both male and female judges, as both would have an incentive to change the law in ways that advantage their daughters. Lastly, we should also see this for Democrat and Republican judges, although detecting the change might be more straightforward for Republicans as opposed to Democrats, many of whom may already have liberal views on these issues.

\section{Fertility Stopping Rules}

We note that factors unrelated to personal relationships could be driving any results. For example, couples may be using "fertility stopping rules" or the practice by which couples continue or stop having children in part based on the gender of the children they already have. ${ }^{9}$ It could be the case, for example, that judges (1) keep having children until they have at least one child of each gender, (2) are conservative and so are content with having had only boys, or (3) are liberal so are content with having had all girls. As we discuss in detail below, finding a "daughters effect" could simply be an artifact of the use of fertility stopping rules. To address concern (1) and to partially address concerns (2) and (3), we more closely examine couples who have only one child-for whom the fertility stopping rules are, as we note later on, less of a concern. Although this is by no means a perfect test of these rules, it does address couples who appear to lack an expressed preference for at least one of each gender. This leads us to a related supposition, which is that the daughters effect should also manifest among judges with only one child.

others more liberal. In this case, then the effects would be muddled, and not particularly discernible across gendered cases versus not.

${ }^{9}$ These sorts of fertility stopping rules are referred to in the demography literature as "differential stopping behavior" (Clark 2000). In the United States, the preference is for gender balance (Freedman, Freedman, and Whelpton 1960; Raley and Bianchi 2006; Sloane and Lee 1983; Yamaguchi and Ferguson 1995). Evidence that this preference has diminished over time is explored in Pollard and Morgan (2002)
TABLE 1 Number of Children and Girls for U.S. Courts of Appeals Judges Participating in Gender-Related Cases, 1996-2002

\begin{tabular}{lccccccccccc}
\hline Number of Children & $\mathbf{0}$ & $\mathbf{1}$ & $\mathbf{2}$ & $\mathbf{3}$ & $\mathbf{4}$ & $\mathbf{5}$ & $\mathbf{6}$ & $\mathbf{7}$ & $\mathbf{8}$ & $\mathbf{9}$ & $\mathbf{N}$ \\
\hline Democrat & 12 & 13 & 33 & 24 & 15 & 4 & - & 1 & - & 1 & 103 \\
Republican & 13 & 8 & 44 & 30 & 15 & 7 & 3 & - & 1 & - & 121 \\
\hline Number of Girls & 0 & 1 & 2 & 3 & 4 & 5 & 6 & 7 & 8 & 9 & \\
Democrats & 26 & 35 & 29 & 10 & 1 & 2 & - & - & - & - & \\
Republicans & 36 & 43 & 31 & 9 & 2 & 0 & - & - & - & - \\
\hline
\end{tabular}

\section{Data and Methods}

We explore these theories using data from the U.S. Courts of Appeals, the middle tier in the federal court system. We choose appellate courts primarily due to data availability. With approximately 200 judges at any given time, we have more data on appellate judges than if we just focused on the nine justices on the U.S. Supreme Court. In addition, although gathering personal information on federal judges is a difficult enterprise (as we discuss in the supporting information), it is more feasible for appellate judges versus district judges. Lastly, the federal appeals courts follow a long-standing practice of not allowing justices to request cases; thus, judges with daughters may not request to hear gender-related cases.

\section{Family Data}

While several databases on appellate judges' personal characteristics exist, we know of no extant data set that contains information on judges' family lives. We therefore collected new data that include the number of children for each appeals judge and how many of them are girls. Table 1 provides a summary. This information was gathered from publicly available sources such as Who's Who in American Law, the CQ Press Judicial Staff Directory, alumni newsletters, newspaper articles, and public announcements such as obituaries. Additional information on how the data were collected is provided in the supporting information. We further combine these data with existing data collected by Zuk, Barrow, and Gryski (2009) on judges' partisanship (party affiliation of the appointing president), birth year, race, gender, and religious identification.

Note that data on the birth order of children were either completely unavailable or impossible to infer, as was information on the approximate age of each child. We also do not have data on whether judges had these 
children before or after 1996, which is when our case data begin. However, the average age at investiture for the judges in our sample is 50.6; by contrast, the mean age for an American man to have his first child is around 25 (Martinez, Daniels, and Chandra 2012). In addition, to the authors' knowledge, no judge in our data appears to have had offspring during the time period in question. Thus, we move forward assuming that these judges have concluded having children before the time frame in question. ${ }^{10}$

\section{Case-Level Data}

To address our various theories, we rely on two caselevel data sets. The first is a randomly selected subset of published Courts of Appeals cases collected and coded by Kuersten and Haire (2007). This data set includes approximately 3,000 cases from 1996 to 2002 and allows us to test the effect of having daughters not just within gender-related cases, but across all legal issue areas (including criminal cases). However, several of our hypotheses specifically posit that judges with daughters will vote in a more liberal fashion only on cases having a gender dimension. Because databases like Kuersten and Haire's have very few such cases, we gathered a second new data set to capture the universe of civil gender-related cases decided by the U.S. Courts of Appeals.

To collect these cases, we started with all of the cases, published and unpublished, ${ }^{11}$ decided from 1996 to $2002^{12}$ that had "gender," "pregnancy," or "sex" in the LexisNexis case classification headings. This initial search yielded approximately 1,450 cases, but it included 134 cases having nothing to do with women's rights (e.g., race-based discrimination cases where gender was mentioned only in passing); we therefore subset this population into cases that explicitly involved (1) employment

\footnotetext{
${ }^{10}$ We note that age of the child could be important in understanding the mechanisms involved. For example, older children could be more likely to engage in lobbying than extremely young children. Although we cannot test this directly (because the data are unavailable), seeing an effect despite this would suggest that we would be presenting a conservative estimate of the effect for older children.

${ }^{11}$ We chose to include unpublished cases as well because having girls could affect the decision to publish an opinion; including both published and unpublished cases avoids such potential bias. This is one advantage to using our new data set versus that of Kuersten and Haire (2007).

${ }^{12}$ For the sake of legal and historical consistency, we focus on cases from June 27, 1996, moving forward. This has the effect of including only those cases that were decided after the last major Supreme Court case involving women's rights issues, United States $v$. Virginia. We choose 2002 as our end point to make this data analysis parallel to the data compiled by Kuersten and Haire (2007).
}

discrimination on the basis of gender by private actors, (2) employment discrimination on the basis of pregnancy by private actors, (3) reproductive rights or abortion, and (4) claims made under Title IX. This left us with 1,325 cases that had a gender component, of which the greatest share $(92 \%)$ were employment discrimination cases. Of these 1,325 cases, 310 were brought by male or transsexual plaintiffs or by plaintiffs representing men's or lesbian, gay, bisexual, and transgender (LGBT) interests. Because these cases did not go to the heart of our inquiry (and because many included male plaintiffs suing for adverse employment decisions due to sexual harassment by the plaintiff), we excluded them.

After discarding cases brought by men or LGBT plaintiffs, we were left with 990 gender-related cases involving discrimination against women or women's rights. For each of these, we collected the names of the appeals court judges on the panel (excluding non-appeals court visiting judges). We also coded the directionality of each of the judges' votes as being (1) antifeminist or (2) partially or entirely feminist. ${ }^{13}$ The feminist decision would be one in which the judge voted in favor of the female plaintiff or in favor of the plaintiff representing women's interest (e.g., if the Equal Employment Opportunity Commission brought a suit on behalf of female employees). The antifeminist decision would be one in which the judge voted in favor of defendant employers or in favor of sustaining a restrictive antiabortion statute. The partially feminist decision would be one in which the judge's vote was mixed, for example, an instance in which the plaintiff won some claims but lost others. The end result was 2,674 unique votes cast by 244 unique appeals court judges.

We were able to track down fertility data for 224 of these judges (Tables 1 and 2). In general, it was more difficult to confirm the absence of children than the presence and sex of children (which we discuss in the supporting information). It is therefore quite likely that many of the judges for whom we are missing fertility data did not have any children, and are not relevant for many of the results discussed in the next section. In addition, we could not find the gender breakdown for the handful of individuals with extremely large numbers of children (e.g., Republican Wallace Clifford, who had 15 children, or Democrat Henry Politz, who had 11); for these individuals, we had no counterpoints to provide comparison, meaning that they would be excluded in any event. Lastly, there is no

\footnotetext{
${ }^{13}$ The results do not hinge on this coding decision; an ordered specification including the partially feminist cases as a separate category is included in Table 5, Model 6 (as well as in Table 6, Model 8 for non-gender-cases), and the results are the same.
} 


\section{TABLE 2 Demographics of U.S. Courts of Appeals Judges Who Voted on Gender-Related Cases, 1996-2002}

\begin{tabular}{lcccrr}
\hline & All & Democrats & Republicans & Women & Men \\
\hline Mean Number of Children & 2.47 & 2.40 & 2.54 & 1.58 & 2.66 \\
Mean Number of. Girls & 1.24 & 1.33 & 1.16 & 0.71 & 1.34 \\
Proportion Who Have 0 Children & 0.11 & 0.12 & 0.11 & 0.29 & 0.08 \\
1 Child & 0.09 & 0.13 & 0.07 & 0.21 & 0.07 \\
2 Children & 0.34 & 0.32 & 0.36 & 0.26 & 0.36 \\
3 Children & 0.24 & 0.23 & 0.25 & 0.13 & 0.26 \\
4 Children & 0.13 & 0.15 & 0.12 & 0.08 & 0.15 \\
5 Children & 0.05 & 0.04 & 0.06 & 0.03 & 0.05 \\
6 Children or More & 0.03 & 0.02 & 0.03 & - & 0.03 \\
Proportion Female & 0.17 & 0.26 & 0.09 & - & - \\
Proportion Republican & 0.54 & - & - & 0.29 & 0.59 \\
Proportion White & 0.91 & 0.78 & 0.99 & 0.93 & 0.91 \\
Mean Year Born & 1932.55 & 1931.23 & 1933.43 & 1938.57 & 1931.49 \\
N & 224 & 103 & 121 & 38 & 186 \\
\hline
\end{tabular}

ex ante reason to believe that any missingness or measurement error would be different for daughters as opposed to sons.

Summary statistics on the 224 judges for whom we could find fertility data are described in Table 2 . These judges have on average 2.47 children per judge, with Republicans having more children on average than Democrats (2.54 versus 2.40-both higher than the population average of 2.1), but the difference in proportion of female children between Democrats and Republicans is small enough to be attributable to chance. Female judges tend to have fewer children than male judges ( 1.58 versus 2.66 ), with nearly $30 \%$ of female judges having zero children. Given the extraordinarily small fraction of judges who have more than five children, we drop these individuals in some of the analyses (which we explain in more detail below).

\section{Methodology}

Our primary explanatory variable is the number of biological daughters each judge has, conditioned on the total number of children, per the methodology of Washington (2008). We treat the number of daughters as categorical variables in order to explore whether the effect of having girls proceeds in a nonlinear fashion. Furthermore, we condition on the total number of children by including fixed effects, which estimates the effects of having girls among judges with the same number of children. ${ }^{14}$

\footnotetext{
${ }^{14}$ Phrasing this in terms of the proportion of children that are daughters would conflate two processes: The proportion would
}

We present results analyzing two different outcome variables. The first is the judge's overall voting record, which we construct by examining the proportion of a judge's votes made in a liberal or feminist direction; Figure 1 depicts this variable for gender-related cases. This measure provides a straightforward analogy to Washington's (2008) legislator voting scores and roll-call vote shares and is less sensitive to potential panel effects. ${ }^{15}$ It also appropriately captures the fact that having daughters (our "treatment") happens at the judge level, not the case level. As such, we use this outcome for most of the analyses we present. We do note, however, that unlike votes taken in Congress, the number of cases, including gender-related cases, heard by each judge varies (see Table 3 for a summary of gender-related cases) due to different lengths of service, different jurisdictions hearing different numbers of cases, etc. We therefore use weighted least squares (WLS) regression with the proportion of cases each judge decided in a liberal/feminist direction as the outcome variable, weighted by the number of cases each judge heard. ${ }^{16}$

increase as the number of daughters increases but alternatively as the number of children decreases. Hence, we would not be able to isolate the daughters effect without further assumptions.

${ }^{15}$ In fact, the composition of Congress changes very little or not at all from vote to vote, whereas judges are likely to be members of very different panels for each vote. Hence, panel effects are likely to be less problematic in the judicial context than the legislative context.

${ }^{16}$ Using ordinary least squares (OLS) regression would violate the assumption of constant variance across observations, as the variance would vary according to the number of cases each judge heard. 


\section{Figure 1 Distribution of the Proportion of Cases Decided in a Feminist Direction out of All Gender-Related Cases Decided, 1996-2002}

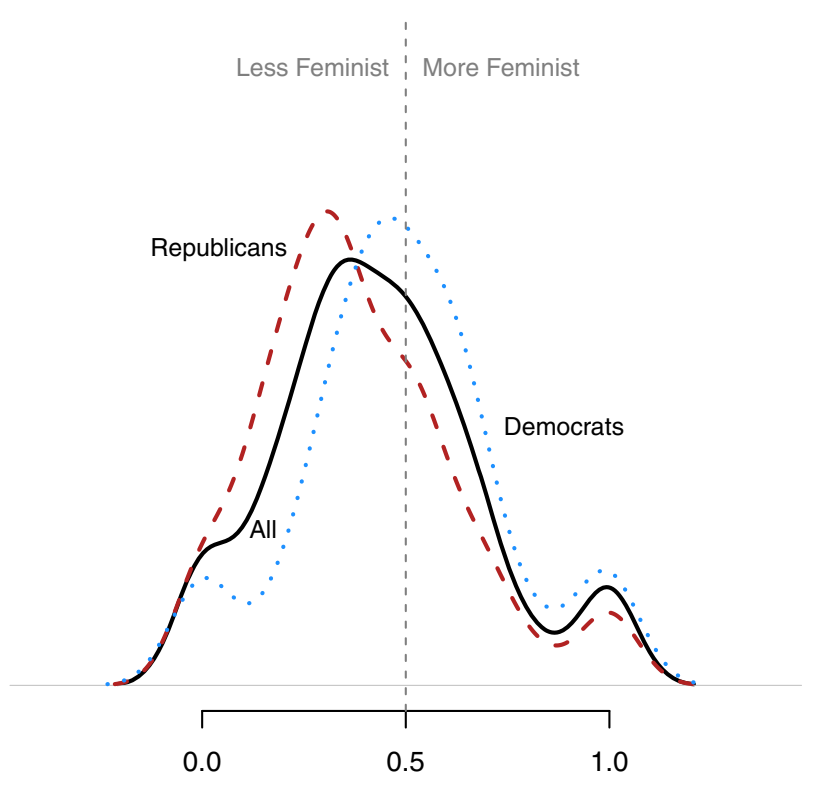

Proportion of Cases Decided in a Feminist Direction

\section{TABLE 3 Distribution of the Number of Gender-Related Cases Heard per Judge, 1996-2002}

\begin{tabular}{lcccccc}
\hline & Min. & 1st Qu. & Median & Mean & 3rd Qu. & Max. \\
\hline All Judges & 1 & 5 & 8 & 11.10 & 14 & 46 \\
Democrats & 1 & 5 & 7 & 10.12 & 13 & 39 \\
Republicans & 1 & 5 & 9 & 11.94 & 14 & 46 \\
\hline
\end{tabular}

As an additional check, and to provide congruence with the courts of appeals literature, we also analyze a second outcome variable, judge-level votes in individual cases. By including circuits- and case-level controls, this measure allows us to control for idiosyncratic circuit or case-level factors that could affect judges' votes. Here, we use logit and ordered logit regressions and include circuit fixed effects, year-by-year fixed effects, issue area fixed effects, and standard errors clustered at the case level. For both types of analyses, we include additional controls that could affect decision making, including partisanship, age, gender, religion (Catholicism), and race. The conclusions from all of the analyses are substantively similar; we therefore present some of these additional analyses in the supporting information.

\section{Results}

We begin by addressing the possibility that personal relationships affect decision making via learning, protectionism, or preference realignment, which all posit that having daughters would push judges leftward on genderrelated cases-a finding in line with the literature on gender and judicial decision making (e.g., Boyd, Epstein, and Martin 2010). We later address the possibility that these findings could extend to non-gender-related cases as well.

\section{Daughters Effect among Gender-Related Cases}

Table 4 presents results in which the outcome variable is the judges' records on voting on gender rights casesthat is, the proportion of cases that each judge decided in a feminist-leaning direction. Model 1 shows the results when we include the number of girls as a categorical variable. More substantively, we compare how the effect varies between having no daughters and having up to five daughters, compared among judges who have the same number of children. The model shows that an increase in the number of girls from none to one, conditional on the total number of children, translates on average into a $9 \%$ increase in the proportion of genderrelated cases in which a judge will vote in a feminist direction. Comparable results are given by looking at increases from zero to two girls, zero to three girls, and zero to five girls, although the small number of judges with so many daughters means that these estimates are statistically insignificant. Surprisingly, we see a negative effect for increases from zero to four girls; however, this effect is based on a very small number of judges and is not close to significant.

Nearly the same substantive result is yielded by Model 2 , in which we include a dummy variable for whether a judge has at least one daughter. Here, having at least one daughter corresponds to a $7 \%$ increase in the proportion of cases in which a judge will vote in a feminist direction. The findings in both Model 1 and Model 2 demonstrate that the greatest change comes simply from having at least one girl; there is no added impact on having additional girls, and the effect does not increase linearly. This is one piece of evidence against the theory that the effect is being driven by daughters lobbying or placing social pressure on their parents; such a lobbying theory would suggest that having daughters would bring additional effects. 
TABLE 4 Weighted Least Squares Results, Gender-Related Cases Only

\begin{tabular}{|c|c|c|c|c|c|c|c|c|}
\hline & \multicolumn{8}{|c|}{ Voting Record in a Feminist Direction, Gender-Related Cases Only } \\
\hline & \multicolumn{4}{|c|}{ All Judges } & \multicolumn{4}{|c|}{ Judges with 1-4 Children } \\
\hline & $(1)$ & (2) & (3) & (4) & (5) & $(6)$ & $(7)$ & (8) \\
\hline At Least 1 Girl & & $\begin{array}{l}0.07^{* *} \\
(0.03)\end{array}$ & $\begin{array}{l}0.09^{* *} \\
(0.04)\end{array}$ & $\begin{array}{l}0.07^{*} \\
(0.04)\end{array}$ & & $\begin{array}{l}0.07^{* *} \\
(0.04)\end{array}$ & $\begin{array}{l}0.09^{* *} \\
(0.04)\end{array}$ & $\begin{array}{l}0.07^{*} \\
(0.04)\end{array}$ \\
\hline 1 Girl & $\begin{array}{l}0.09^{* *} \\
(0.04)\end{array}$ & & & & $\begin{array}{l}0.09^{* *} \\
(0.04)\end{array}$ & & & \\
\hline 2 Girls & $\begin{array}{c}0.05 \\
(0.04)\end{array}$ & & & & $\begin{array}{c}0.05 \\
(0.04)\end{array}$ & & & \\
\hline 3 Girls & $\begin{array}{c}0.06 \\
(0.06)\end{array}$ & & & & $\begin{array}{c}0.08 \\
(0.07)\end{array}$ & & & \\
\hline 4 Girls & $\begin{array}{l}-0.35 \\
(0.46)\end{array}$ & & & & & & & \\
\hline 5 Girls & $\begin{array}{c}0.27 \\
(0.17)\end{array}$ & & & & & & & \\
\hline Republican & & & $\begin{array}{c}-0.15^{* * *} \\
(0.04)\end{array}$ & $\begin{array}{c}-0.17^{* * *} \\
(0.03)\end{array}$ & & & $\begin{array}{c}-0.15^{* * *} \\
(0.04)\end{array}$ & $\begin{array}{c}-0.17^{* * *} \\
(0.04)\end{array}$ \\
\hline Age & & & $\begin{array}{c}0.01^{* *} \\
(0.002)\end{array}$ & $\begin{array}{c}0.004 \\
(0.002)\end{array}$ & & & $\begin{array}{c}0.004 \\
(0.003)\end{array}$ & $\begin{array}{c}0.004 \\
(0.003)\end{array}$ \\
\hline Catholic & & & $\begin{array}{l}-0.08^{* *} \\
(0.03)\end{array}$ & $\begin{array}{l}-0.08^{* *} \\
(0.03)\end{array}$ & & & $\begin{array}{l}-0.06 \\
(0.04)\end{array}$ & $\begin{array}{l}-0.05 \\
(0.03)\end{array}$ \\
\hline Woman & & & $\begin{array}{l}-0.08^{*} \\
(0.05)\end{array}$ & $\begin{array}{l}-0.07^{*} \\
(0.04)\end{array}$ & & & $\begin{array}{l}-0.05 \\
(0.05)\end{array}$ & $\begin{array}{l}-0.04 \\
(0.05)\end{array}$ \\
\hline African American & & & $\begin{array}{l}-0.06 \\
(0.07)\end{array}$ & $\begin{array}{l}-0.06 \\
(0.07)\end{array}$ & & & $\begin{array}{l}-0.04 \\
(0.08)\end{array}$ & $\begin{array}{l}-0.05 \\
(0.08)\end{array}$ \\
\hline Hispanic & & & $\begin{array}{l}-0.11 \\
(0.11)\end{array}$ & $\begin{array}{l}-0.10 \\
(0.10)\end{array}$ & & & $\begin{array}{l}-0.17 \\
(0.12)\end{array}$ & $\begin{array}{l}-0.17 \\
(0.11)\end{array}$ \\
\hline $\begin{array}{l}\text { Child Fixed Effects } \\
\text { Circuit Fixed Effects }\end{array}$ & $\sqrt{ }$ & $\sqrt{ }$ & $\sqrt{ }$ & $\begin{array}{l}\sqrt{ } \\
\sqrt{ }\end{array}$ & $\sqrt{ }$ & $\sqrt{ }$ & $\sqrt{ }$ & $\begin{array}{l}\sqrt{ } \\
\sqrt{ }\end{array}$ \\
\hline Constant & $\begin{array}{c}0.39^{* * *} \\
(0.04)\end{array}$ & $\begin{array}{l}0.39^{* * *} \\
(0.04)\end{array}$ & $\begin{array}{l}0.30^{* *} \\
(0.13)\end{array}$ & $\begin{array}{c}0.54^{* * *} \\
(0.14)\end{array}$ & $\begin{array}{l}0.31^{* * *} \\
(0.04)\end{array}$ & $\begin{array}{l}0.32^{* * *} \\
(0.04)\end{array}$ & $\begin{array}{l}0.29^{*} \\
(0.16)\end{array}$ & $\begin{array}{l}0.43^{* *} \\
(0.17)\end{array}$ \\
\hline $\mathrm{N}$ & 224 & 224 & 161 & 161 & 182 & 182 & 130 & 130 \\
\hline R-squared & 0.06 & 0.04 & 0.21 & 0.42 & 0.04 & 0.03 & 0.19 & 0.39 \\
\hline Adj. R-squared & -0.01 & -0.01 & 0.12 & 0.30 & 0.01 & 0.01 & 0.13 & 0.28 \\
\hline
\end{tabular}

Note: Outcome is proportion of feminist votes. Models 1-4 are for all judges, and Models 5-8 are for judges with 1-4 children. (No judge among those with 1-4 children had four girls.) All models include fixed effects for number of children and use weights based on the number of cases heard by each judge. ${ }^{* * *} \mathrm{p}<.01,{ }^{* *} \mathrm{p}<.05,{ }^{*} \mathrm{p}<.10$.

Given that we see little movement with additional daughters, we move forward by collapsing explanatory variables to look at the effect of having at least one daughter, conditioning on the total number of children (Model 2 ). We are also mindful of the extremely small number of judges with five or more children. The small sample size in these groups leads to an inability to estimate the effects among this group with any precision, as seen in Model 1. Mindful that these 17 judges could be driving the results, we also present results limiting the space to those between one and four-who collectively represent
$92 \%$ of all judges. These results are presented in Models 5-8 in Table 4 and demonstrate that the effect of having daughters is strong and significant: Having at least one girl results in an approximate $7 \%$ increase in the share of cases in which a judge will vote in a feminist direction. The results are even stronger if we limit the sample space to the $80 \%$ of judges with fewer than four children; because the effect for judges with four children appears mixed, we include the four-child judges in the interest of transparency and presenting conservative results. Because these results are comparable in all respects, 
and because they reduce reliance on a small sample of unusually highly fertile judges, we move forward comparing judges with four children or fewer in subsequent analyses. As a point of comparison, we also present several other model specifications in Tables 4. For example, in Table 4, Models 3, 4, 7, and 8, we include additional covariates that might be predictive of judges' voting on gender-related issues, including partisanship, gender, and race. ${ }^{17}$ We also include circuit fixed effects in Models 4 and 8.

In Table 5, we demonstrate the effect of having daughters on individual judge-votes, at the case level (i.e., the probability that a judge will vote in a feminist direction in any given gender-related case). Table 5, Model 1 again shows that the effect primarily comes from parenting one girl, which we verify in Model 2. We include additional controls in Table 5, Model 3 (partisanship, gender, and race), Model 4 (circuit, year, and issue area fixed effects), and Model 5 (standard errors that are calculated via a bootstrap clustered on the case). Lastly, as a further guard against the possibility of the results being driven by how the outcome variable is stylized, we use an ordered logit specification, with the outcome being whether the judge voted in an antifeminist, mixed/partially feminist, or feminist direction; this last model also includes bootstrap clustered standard errors. The results are substantively the same, with the impact of having daughters being a positive and significant predictor of increased feminist voting under all model specifications.

\section{Daughters Effect on Other Cases}

As suggested by the theory of lobbying and protectionism, the influence of having daughters may extend across all cases, not just those having a gendered component. Thus, Table 6 presents parallel results on the data collected and coded by Kuersten and Haire (2007), which include a subset of approximately 3,000 randomly selected published cases (1996-2002) across all issue areas. ${ }^{18}$ Models 1-3 replicate the analysis examining each judge's record of voting in a liberal direction across these cases, and Models 4-7 present the outcome variable as a judge-level caseby-case vote. Model 8 stylizes the outcome variable as

\footnotetext{
${ }^{17}$ Note that there is some missingness in this judge demographic data; rerunning the original analyses on the smaller subset that had no missingness results in substantively identical results, which leads us to believe that the data are essentially missing fairly randomly.

${ }^{18}$ In analyses not shown, we verify that the daughters effect is indeed present for civil gender-related cases in the Kuersten and Haire (2007) data.
}

whether the judge voted in a conservative, mixed and/or moderate, or liberal direction. ${ }^{19}$ Under all model specifications, and with different kinds of controls, the effect of having daughters is null. We replicate these results for criminal law cases only, shown in the supplemental information; the effects associated with having daughters are likewise null. Taken together, the results demonstrate that the existence of the daughters effect can only be established for civil cases having a gendered dimension. As we discuss below, this is evidence against several possible mechanisms, including lobbying and protectionism, which would both predict an effect outside of the gendered context.

\section{Daughters Effect by Party}

Now that we have ruled out that the daughters effect applies to non-gender related cases, we turn to examining the effect within gender cases more closely. We begin by examining whether the effect varies by party. ${ }^{20}$ As we note earlier, if having daughters pushes judges to the left, as is seen on gender issues, then we should be able to detect this more easily for Republican judges, who are less likely to vote in a liberal direction on these issues a priori.

The first two columns of Table 7 present results that are disaggregated by the party of the appointing president. Model 1 presents the results for judges who were appointed by a Republican president, and Model 2 presents the results for judges who were appointed by a Democratic president. As before, the outcome variable is the proportion of cases a judge decided in a feminist direction on gender-related cases. Comparing the two models makes it clear that the effect is being driven by Republican judgesthe effect for Republican judges is an average $7 \%$ increase in the proportion of cases decided in a feminist direction (and significant at the 10\% level, with a p-value of .09, for judges with fewer than five children, and at the $5 \%$ level, with p-value of .03, for judges with fewer than four children) whereas the effect for Democrat judges is on average $4 \%$ and is not signifiant under any model specification or population subset. Thus, we see some evidence in favor of the idea that the daughters effect works primarily for

\footnotetext{
${ }^{19}$ Models 6, 7, and 8 also include fixed effects for legal issue area. These include (1) criminal law, (2) civil rights, (3) First Amendment, (4) due process, (5) privacy, (6) labor relations, (7) economic activity and regulation, and (8) miscellaneous or not ascertained (Kuersten and Haire 2007).

${ }^{20}$ We note that partisanship could be affected by the act of having a daughter, making it posttreatment. Although this appears not to be a large concern (differences in the proportion of daughters between Republicans and Democrats are not significant), we nonetheless are mindful of the posttreatment issues and therefore aim primarily to examine whether the effect varies across subsets.
} 


\section{TABLE 5 Logit and Ordered Logit Results, Gender-Related Cases Only}

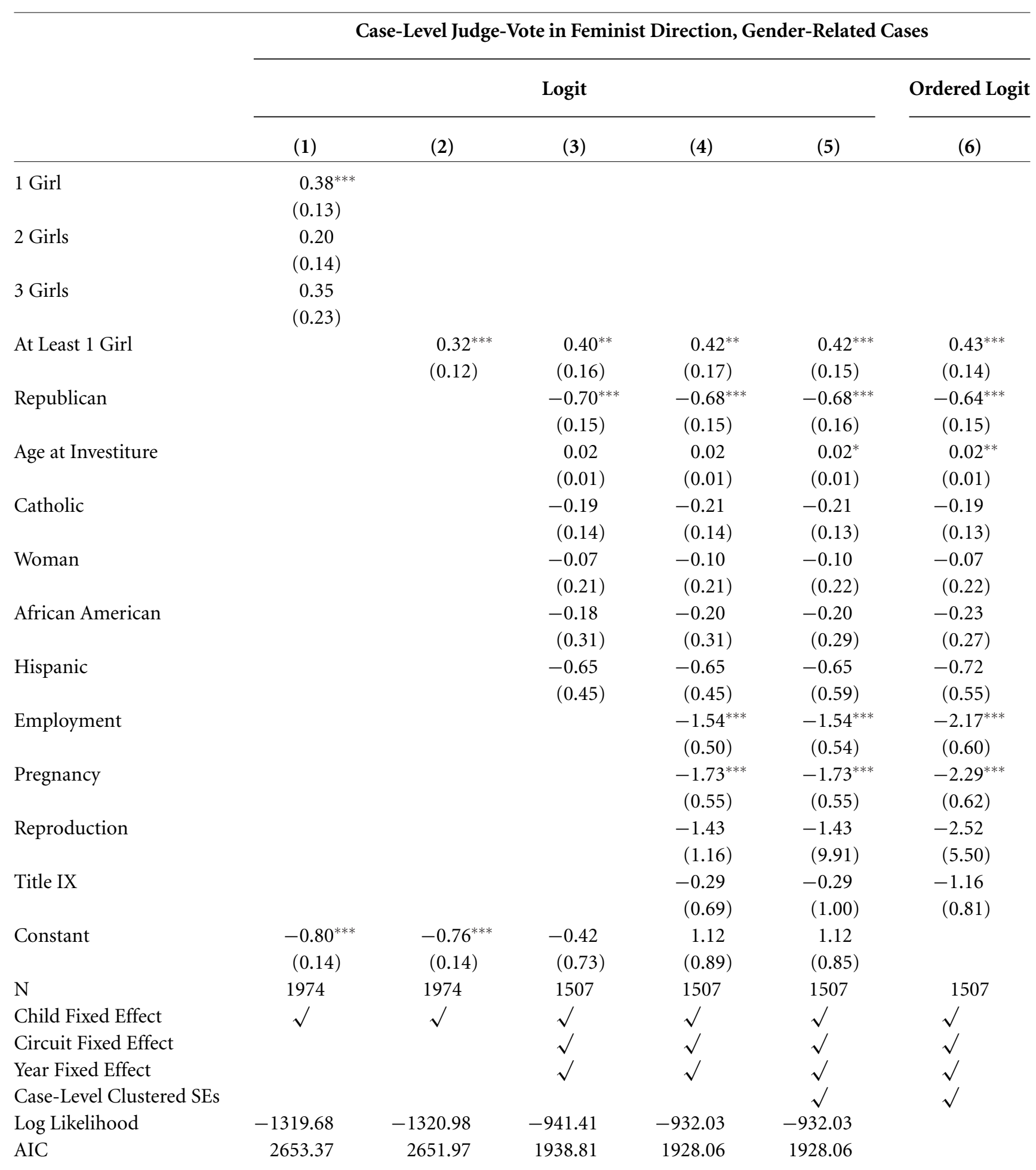

Note: Outcome is whether the judge in a case votes in a feminist direction (Models 1-5) or in an antifeminist, partially feminist, or feminist direction (Model 6). All models include fixed effects for total number of children, and Models 3-6 include circuit and year fixed effects. Models 5 and 6 additionally include standard errors clustered at the case level. ${ }^{* * *} \mathrm{p}<.01,{ }^{* *} \mathrm{p}<.05,{ }^{*} \mathrm{p}<.10$. 
TABLE 6 Weighted Least Squares, Logit, and Ordered Logit Results, All Cases

\begin{tabular}{|c|c|c|c|c|c|c|c|c|}
\hline & \multicolumn{8}{|c|}{ Case-Level Judge-Vote in Liberal Direction, All Cases } \\
\hline & \multicolumn{3}{|c|}{ WLS } & \multicolumn{4}{|c|}{ Logit } & \multirow{2}{*}{$\begin{array}{c}\text { Ordered Logit } \\
(8)\end{array}$} \\
\hline & $(1)$ & $(2)$ & (3) & $(4)$ & $(5)$ & $(6)$ & $(7)$ & \\
\hline At Least 1 Girl & $\begin{array}{c}0.04 \\
(0.03)\end{array}$ & $\begin{array}{c}0.04 \\
(0.03)\end{array}$ & $\begin{array}{c}0.01 \\
(0.03)\end{array}$ & $\begin{array}{c}0.02 \\
(0.10)\end{array}$ & $\begin{array}{c}0.18 \\
(0.11)\end{array}$ & $\begin{array}{c}0.01 \\
(0.12)\end{array}$ & $\begin{array}{c}0.01 \\
(0.12)\end{array}$ & $\begin{array}{l}0.0002 \\
(0.12)\end{array}$ \\
\hline Republican & & $\begin{array}{c}-0.04 \\
(0.03)\end{array}$ & $\begin{array}{r}-0.05^{*} \\
(0.03)\end{array}$ & & $\begin{array}{c}-0.21^{* *} \\
(0.09)\end{array}$ & $\begin{array}{c}-0.23^{* *} \\
(0.10)\end{array}$ & $\begin{array}{c}-0.23^{* *} \\
(0.10)\end{array}$ & $\begin{array}{c}-0.26^{* *} \\
(0.10)\end{array}$ \\
\hline Age at Investiture & & $\begin{array}{c}-0.001 \\
(0.002)\end{array}$ & $\begin{array}{c}-0.001 \\
(0.002)\end{array}$ & & $\begin{array}{c}-0.004 \\
(0.01)\end{array}$ & $\begin{array}{r}-0.001 \\
(0.01)\end{array}$ & $\begin{array}{r}-0.001 \\
(0.01)\end{array}$ & $\begin{array}{r}-0.001 \\
(0.01)\end{array}$ \\
\hline Catholic & & $\begin{array}{c}-0.05 \\
(0.03)\end{array}$ & $\begin{array}{c}-0.02 \\
(0.03)\end{array}$ & & $\begin{array}{c}-0.19^{* *} \\
(0.09)\end{array}$ & $\begin{array}{c}-0.10 \\
(0.10)\end{array}$ & $\begin{array}{c}-0.10 \\
(0.09)\end{array}$ & $\begin{array}{c}-0.09 \\
(0.09)\end{array}$ \\
\hline Woman & & $\begin{array}{r}-0.001 \\
(0.04)\end{array}$ & $\begin{array}{r}0.001 \\
(0.04)\end{array}$ & & $\begin{array}{c}-0.02 \\
(0.12)\end{array}$ & $\begin{array}{c}0.01 \\
(0.14)\end{array}$ & $\begin{array}{c}0.01 \\
(0.14)\end{array}$ & $\begin{array}{c}-0.02 \\
(0.13)\end{array}$ \\
\hline African American & & $\begin{array}{c}0.02 \\
(0.07)\end{array}$ & $\begin{array}{c}-0.04 \\
(0.06)\end{array}$ & & $\begin{array}{c}0.04 \\
(0.20)\end{array}$ & $\begin{array}{c}-0.08 \\
(0.23)\end{array}$ & $\begin{array}{c}-0.08 \\
(0.22)\end{array}$ & $\begin{array}{c}-0.09 \\
(0.21)\end{array}$ \\
\hline Hispanic & & $\begin{array}{c}0.02 \\
(0.09)\end{array}$ & $\begin{array}{c}-0.03 \\
(0.08)\end{array}$ & & $\begin{array}{c}0.05 \\
(0.28)\end{array}$ & $\begin{array}{c}-0.13 \\
(0.31)\end{array}$ & $\begin{array}{c}-0.13 \\
(0.29)\end{array}$ & $\begin{array}{c}-0.13 \\
(0.29)\end{array}$ \\
\hline $\begin{array}{l}\text { Child Fixed Effects } \\
\text { Circuit Fixed Effect } \\
\text { Year Fixed Effect } \\
\text { Issue Area Dummy } \\
\text { Case-Level Clustered SEs }\end{array}$ & $\sqrt{ }$ & $\sqrt{ }$ & $\begin{array}{l}\sqrt{ } \\
\sqrt{ }\end{array}$ & $\begin{array}{l}\sqrt{ } \\
\sqrt{ }\end{array}$ & $\sqrt{ }$ & $\begin{array}{l}\sqrt{ } \\
\sqrt{ } \\
\sqrt{ } \\
\sqrt{ }\end{array}$ & $\begin{array}{l}\sqrt{ } \\
\sqrt{ } \\
\sqrt{ } \\
\sqrt{ } \\
\sqrt{ }\end{array}$ & $\begin{array}{l}\sqrt{ } \\
\sqrt{ } \\
\sqrt{ } \\
\sqrt{ } \\
\sqrt{ }\end{array}$ \\
\hline Constant & $\begin{array}{l}0.42^{* * *} \\
(0.03)\end{array}$ & $\begin{array}{l}0.49^{* * *} \\
(0.12)\end{array}$ & $\begin{array}{l}0.45^{* * *} \\
(0.12)\end{array}$ & $\begin{array}{c}-0.49^{* * *} \\
(0.15)\end{array}$ & $\begin{array}{c}0.04 \\
(0.38)\end{array}$ & $\begin{array}{l}-14.22 \\
(488.52)\end{array}$ & $\begin{array}{c}-14.22^{* * *} \\
(4.74)\end{array}$ & \\
\hline $\mathrm{N}$ & 189 & 133 & 133 & 3778 & 3171 & 3171 & 3171 & 3171 \\
\hline R-squared & 0.04 & 0.08 & 0.42 & & & & & \\
\hline Adj. R-squared & 0.02 & 0.001 & 0.31 & & & & & \\
\hline
\end{tabular}

Note: Data collected and coded by Kuersten and Haire (2007). Outcome is the judge's overall liberal voting record weighted by number of cases (Models 1-3), whether she or he voted in a liberal or partially liberal direction in an individual case (Models 4-7), or whether he or she voted in a conservative, mixed, or liberal direction in an individual case (Model 8). Models 7 and 8 additionally include standard errors clustered at the case level. ${ }^{* * *} \mathrm{p}<.01,{ }^{* *} \mathrm{p}<.05,{ }^{*} \mathrm{p}<.10$.

individuals whose political affiliations suggest that they would otherwise be conservative. ${ }^{21}$ However, the difference between Democrats and Republicans is not statistically significant at traditional levels. This is consistent with Washington (2008).

\section{Daughters Effect by Gender}

Several of our theories-for example, learning—suggest that we should see an effect for men, but not for women.

\footnotetext{
${ }^{21}$ Taking the outcome variable at the case level and including an ordered logit specification (not shown) does not affect these results; there is no discernible liberalizing effect among Democrats.
}

However, a difficulty of analyzing the effect across gender is that the pool of female judges differs markedly from the pool of male judges. As Table 2 shows, there are fewer women than men on the appellate courts during this period. Additionally, female judges are more likely than male judges to have no children (29\% versus $8 \%)$ and on average have fewer children as well (1.58 versus 2.66 ). Mindful of the small sample size, Models 3 and 4 of Table 7 include the gender of the judge. We do find a strong and significant effect for the male judges (Model 3); however, the effect for female judges is both small and insignificant. (In addition, an interaction between daughters and judge gender is also not significant.) Given the small number of women, and the smaller number who have children, 
TABLE 7 Weighted Least Squares Results

\section{Share of Votes in Feminist Direction}

\begin{tabular}{lccccc} 
& Model 1 & Model 2 & Model 3 & Model 4 & Model 5 \\
\hline At Least 1 Girl & $0.07^{*}$ & 0.04 & $0.08^{* *}$ & 0.05 & $0.08^{*}$ \\
& $(0.04)$ & $(0.05)$ & $(0.04)$ & $(0.08)$ & $(0.04)$ \\
2 Children & -0.005 & $0.10^{*}$ & 0.03 & 0.08 & 0.02 \\
& $(0.06)$ & $(0.06)$ & $(0.05)$ & $(0.09)$ & $(0.07)$ \\
3 Children & -0.01 & 0.08 & 0.04 & -0.01 & 0.01 \\
& $(0.06)$ & $(0.06)$ & $(0.06)$ & $(0.10)$ & $(0.07)$ \\
4 Children & -0.07 & $0.19^{* *}$ & 0.02 & 0.01 & -0.06 \\
& $(0.07)$ & $(0.08)$ & $(0.07)$ & $(0.13)$ & $(0.08)$ \\
Constant & $0.30^{* * *}$ & $0.35^{* * *}$ & $0.30^{* * *}$ & $0.34^{* * *}$ & $0.28^{* * *}$ \\
& $(0.06)$ & $(0.06)$ & $(0.06)$ & $(0.06)$ & $(0.07)$ \\
N & 97 & 85 & 156 & 26 & 90 \\
R-squared & 0.04 & 0.09 & 0.03 & 0.08 & 0.05 \\
Adj. R-squared & -0.004 & 0.05 & 0.01 & -0.09 & 0.001 \\
\hline
\end{tabular}

Note: Outcome is judges' proportion of feminist votes on gender-related cases. All models include fixed effects for total number of children and use weights based on the number of cases heard by each judge. ${ }^{* * *} \mathrm{p}<.01,{ }^{* *} \mathrm{p}<.05,{ }^{*} \mathrm{p}<.10$.

we cannot rule out that there is no relationship between having girls and voting in a more feminist direction on gender-related cases. However, taken together with the results presented in Model 5, this is strong suggestive evidence that the effect is driven primarily by Republicans and, in particular, Republican men (Model 5).

\section{Daughters Effect for Single-Child Judges}

An alternative, nonempathetic-based explanation behind these findings is the use of fertility stopping rules, or that judges who are progressive on gender issues are content with stopping having children when they have only girls. Although we cannot fully rule this out as a possibility, we display results in Table 8 from models that include only the 46 judges with zero children and one child (Model 1) or one child (Models 2 and 3). This group, because they have only one child, appears not to have the expressed preference for gender parity that is common in the United States. Within this subset, including additional controls becomes impossible because of the small sample size. However, having one daughter as opposed to one son is linked to an even higher $16 \%$ increase in the proportion of gender-related cases decided in a feminist direction. Despite the smaller sample size, the effect is significant at the $5 \%$ level, with a p-value of .03. The effect persists after including controls for party of the appointing president, as shown in Table 8, Model

\section{TABLE 8 Weighted Least Squares Results}

\begin{tabular}{lccc}
\hline & \multicolumn{3}{c}{ Voting Record in Feminist Direction } \\
\cline { 2 - 4 } & $\begin{array}{c}\text { 0 or 1 Child } \\
(\mathbf{1})\end{array}$ & $\begin{array}{c}\text { 1 Child } \\
(\mathbf{2})\end{array}$ & $\begin{array}{c}\text { 1 Child } \\
(\mathbf{3})\end{array}$ \\
\hline 1 Girl & $0.161^{* *}$ & $0.161^{* *}$ & $0.159^{* *}$ \\
& $(0.080)$ & $(0.068)$ & $(0.069)$ \\
1 Child & $-0.119^{*}$ & & \\
& $(0.067)$ & & \\
Republican & & & -0.037 \\
& & & $(0.069)$ \\
Constant & $0.393^{* * *}$ & $0.274^{* * *}$ & $0.292^{* * *}$ \\
& $(0.037)$ & $(0.047)$ & $(0.059)$ \\
N & 46 & 21 & 21 \\
R-squared & 0.097 & 0.230 & 0.242 \\
Adj. R-squared & 0.055 & 0.189 & 0.158 \\
\hline
\end{tabular}

Note: Outcome is judges' proportion of feminist votes on genderrelated cases. Model 1 includes judges with either zero children or one child, whereas Models 2-3 include judges with one child only. All models include fixed effects for total number of children and use weights based on the number of cases heard by each judge. ${ }^{* * *} \mathrm{p}$ $<.01,{ }^{* *} \mathrm{p}<.05,{ }^{*} \mathrm{p}<.10$.

3. (Comparable results at the case level are included in the supporting information.) However, it could still be the case that these couples are still somehow exercising gender-related stopping preferences, which we discuss below. 


\section{Why a "Daughters Effect"?}

Our results clearly demonstrate a liberalizing effect of having daughters among judges voting in gender-related cases. How the effect works, however, is less clear. For example, one explanation might be that judges are trying to protect, or shield, their daughters. That is, the effect of having daughters comes primarily via judges trying to rule in favor of policies that would protect their daughters from emotional or physical harm. However, our results allow us to partially rule out this protectionist explanation: Given that we see an effect only in gender-related civil cases, and not criminal cases, we have no reason to think that simple parental instincts to protect or to shield are behind the effect. If they were, we would likely see some conservative shift among criminal cases, particularly rape or sexual assault cases; we see no evidence of this (see supporting information).

We also rule out that the effect could be driven by most forms of lobbying or social pressure. To see this sort of effect at its clearest, we would need to assume, arguendo, that all girls pull parents in the same (e.g., liberal) direction, which would translate into a uniform pull across all kinds of cases. We see some limited evidence of the first component, with girls pulling parents in more liberal directions on gender-related cases, but none at all of the second regarding all cases. Indeed, as evidenced by Table 6, we see no relationship between having daughters and voting more liberally overall. In addition, we see no evidence that the effect increases along with the number of daughters (i.e., as additional daughters apply additional social pressure); rather, the effect comes primarily from having one girl. Lastly, if we relaxed the assumption that all girls pull their parents in the same direction, we would see muddled effects throughout; the fact that we see fairly clear effects when it comes to gender-related cases is additional evidence that this explanation is fairly unlikely. 22

This leaves two explanations as the most viable. The first is preference realignment, or that having daughters changes judges' preferences in response to changing costs and benefits (Warner 1991). For example, as the costs to them of having unemployed daughters rise, judges may opt against allowing discriminatory practices. Under this

\footnotetext{
${ }^{22}$ We could assume that daughters only lobby in a liberal direction on cases having a gendered dimension and do not lobby on other kinds of cases; however, this is a strong assumption, and we see no reason why this would be the case or, at the very least, why it would be so lopsided as suggested by our results. Under that additional assumption, however, we do note that the observable implications of this lobbying theory would be essentially identical to the learning narrative.
}

theory, we would expect to see, as we do here, that judges with daughters would vote in a more liberal fashion on gender-related cases but less so on other sorts of cases. We would also see that the effect materializes as soon as a judge has one daughter. The second theory is learning, or that having daughters leads judges to learn about issues that they ordinarily would not be exposed to-such as discrimination on the basis of pregnancy, Title IX, and reproductive rights issues. Again, we would expect to see this among gender-related cases only. In addition, we would expect that the most "learning" happens with having at least one girl.

Although we note that definitively adjudicating between the two theories is difficult, we see some suggestive evidence in favor of the learning theory versus the preference realignment theory. We do so because, although we note that an interaction between daughters and a judge being female is not significant, it is clear that the effect is driven primarily by the men in the sample (Table 7). This suggestive finding is consistent with the learning theory, but not the preference realignment theory. For example, female judges will already have firsthand experience with the difficulties of being female and in the workplace. They may already know the challenges of being young and in need of reproductive rights services. And they could have firsthand experience with the fact that very few women played university sports before Title IX. Male judges, however, may not have this firsthand experience; for them, the experience of having daughters could introduce them to the challenges faced by young women. Under the realignment theory, however, both men and women would have incentives to liberalize employment discrimination law or Title IX. However, we do not see an effect when we subset the data to examine women only, although the sample size is quite small.

We also note that the data do not definitively rule out that judges might be using fertility stopping rules. However, three suggestive pieces of evidence move us away from fertility stopping rules being the exclusive explanation. First, the daughters effect remains intact when we examine judges with only one child, for whom concerns about fertility stopping rule usage are minimal. Second, if it is true that more liberal judges continue having children until they have at least one girl (or that more conservative judges are content to "stop" with having all boys), then this would mean that having girls is correlated with across-the-board liberal beliefs-which would translate into liberal voting across all cases. We have no evidence of this (Table 6). Lastly, although we do see in Table 9 some evidence of the possible use of fertility stopping rules across party, the daughters effect persists when subsetting the data to just Republicans. For fertility stopping rules 


\section{TABLE 9 Proportion of Girls (Conditional on Number of Children) for U.S. Courts of Appeals Judges Participating in Gender-Related Cases, 1996-2002}

\begin{tabular}{|c|c|c|c|c|c|c|c|c|c|c|c|c|}
\hline & \multicolumn{6}{|c|}{ Democrats } & \multicolumn{6}{|c|}{ Republicans } \\
\hline & 0 Girls & 1 Girl & 2 Girls & 3 Girls & 4 Girls & 5 Girls & 0 Girls & 1 Girl & 2 Girls & 3 Girls & 4 Girls & 5 Girls \\
\hline 1 Child & 0.46 & 0.54 & - & - & - & - & 0.38 & 0.62 & - & - & - & \\
\hline 2 Children & 0.15 & 0.48 & 0.36 & - & - & - & 0.32 & 0.50 & 0.18 & - & - & - \\
\hline 3 Children & 0.08 & 0.46 & 0.33 & 0.12 & - & - & 0.13 & 0.37 & 0.37 & 0.13 & - & - \\
\hline 4 Children & 0.07 & 0.07 & 0.53 & 0.33 & 0 & - & 0.07 & 0.27 & 0.60 & 0.07 & 0 & - \\
\hline 5 Children & 0 & 0 & 0.25 & 0.50 & 0 & 0.25 & 0.14 & 0.00 & 0.43 & 0.29 & 0.14 & 0 \\
\hline 7 Children & 0 & 0 & 0 & 0 & 1 & 0 & 0 & 0.33 & 0 & 0.67 & 0 & 0 \\
\hline 9 Children & 0 & 0 & 0 & 0 & 0 & 1 & 0 & 0 & 0 & 0 & 1 & 0 \\
\hline
\end{tabular}

to call this into question would mean that there would have to be differentially applied stopping rules within the Republican subset, something for which we have no evidence. However, we note that this is suggestive evidence, and fertility stopping rules cannot be conclusively ruled out.

We also consider, as in Washington (2008), whether the results are driven by selection bias-that is, whether the decision to become a judge (or the decision by the president to appoint someone as a judge) could be driven by having daughters, and that this is driving the effect. We would see this, for example, if conservative judges who have daughters are more likely to seek employment elsewhere and not in the federal judiciary. However, if this selection was happening, we should see a liberalizing effect for having daughters across all cases, not just gender-related cases. This is ruled out by Table 6 .

\section{Conclusion}

Political science scholarship on the courts has mostly focused on the decision-making impact of two important attributes: preferences (e.g., legal philosophy, ideology) and ascriptive characteristics (e.g., race, gender). Less well developed is the notion that personal relationships and experiences-including contacts with close family members-could help us understand how judges decide cases.

In this article, we presented evidence that personal relationships can in fact affect judges' voting. Indeed, across cases involving gender issues, judges who parent daughters as opposed to sons are more likely to reach liberal decisions-possibly because having daughters causes judges to learn about women's issues (Bolzendahl and
Myers 2004; Reingold and Foust 1998). These results are in line with similar studies in a congressional context (Washington 2008) as well as those in the public opinion context (Shafer and Malhotra 2011; Warner 1991; Warner and Steel 1999). Taken together, our results also suggest that existing theories of judicial politics need to be expanded. Decision making can be predicted by a theory that relies on (1) law and partisanship, (2) strategy, (3) identity, and, as we show in this article, (4) personal relationships and experiences.

Three points are further worth noting. First, we use daughters as an example primarily because it allows us to avoid the problem of homophily. Other personal relationships could, however, be equally if not more meaningfulfor example, having a gay or lesbian child or sibling (e.g., Dick Cheney's daughter or Newt Gingrich's sister), or having a disabled or mentally ill son or daughter (e.g., Sarah Palin's youngest son). Second, and relatedly, the effect of having daughters operates primarily in cases with a gendered dimension. (In this regard, our results complement not only Washington's 2008 analysis of congressional representatives, but also Boyd, Epstein, and Martin's 2010 analysis of female judges.) Thus, we posit that to the extent that these sorts of personal relationships help predict judges' voting, it may be only on cases having a natural or substantive connection to that personal relationship. Thus, having daughters affects judges on how they vote on cases that directly relate to issues important to young women. We would expect to see similar close connections between substantive issues and other kinds of personal relationships.

Third, this fact has broader implications for descriptive representation on the courts. Scholarship has demonstrated that female judges decide cases differently from men (Boyd, Epstein, and Martin 2010), and that African Americans also decide cases differently from whites (Cox 
and Miles 2008). However, what we see here is that male judges who have daughters are more likely to vote in a liberal direction-despite not having those ascriptive characteristics that would otherwise be linked to more progressive views on women's rights issues. To this extent, despite Sonia Sotomayor's comment that "a wise Latina woman with the richness of her experiences would more often than not reach a better conclusion than a white male who hasn't lived that life," we find that empathy could be a crosscutting effect. Indeed, what the quasi-experiment of daughters shows is that the transformative impact of personal relationships is not, and need not be, limited to one group or one party.

\section{References}

Baldez, Lisa, Lee Epstein, and Andrew D. Martin. 2006. "Does the U.S. Constitution Need an ERA?" Journal of Legal Studies 35(1): 243-83.

Bogan, Vicki L. 2013. "Investment Decisions and Offspring Gender." Applied Economics 45(31): 4393-406.

Bolzendahl, Catherine I., and Daniel J. Myers. 2004. "Feminist Attitudes and Support for Gender Equality: Opinion Changein Women and Men, 1974-1998." Social Forces 83(2): 759-89.

Boyd, Christina L., Lee Epstein, and Andrew D. Martin. 2010."Untangling the Causal Effects of Sex on Judging." American Journal of Political Science 54(2): 389-411.

Campbell, Angus, Philip E. Converse, Warren E. Miller and Donald E. Stokes. 1966. The American Voter. New York: Wiley.

Clark, Shelley. 2000. "Son Preference and Sex Composition of Children: Evidence from India.” Demography 37(1): 95-108.

Colby, Thomas B. 2012. "In Defense of Judicial Empathy." Minnesota Law Review 96: 1944-2015.

Coltrane, Scott. 1997. Family Man: Fatherhood, Housework, and Gender Equity. New york: Oxford University Press.

Condry, Sandra McConnell, John C., Condry Jr., and Lee Wolfram Pogatshnik. 1983. "Sex Differences: A Study of the Ear of the Beholder." Sex Roles 9(6): 697-704.

Conley, Dalton, and Emily Rauscher. 2013. "The Effect of Daughters on Partisanship and Social Attitudes toward Women." Sociological Forum 28(4): 700-18.

Cox, Adam B., and Thomas J. Miles. 2008. "Judging the Voting Rights Act.” Columbia Law Review 108(1): 1-54.

Davis, Sue, Susan Haire, and Donald R. Songer. 1993. "Voting Behavior and Gender on the U.S. Courts of Appeals." Judicature 77: 129-33.

Denny, Kevin. 2008. "Big and Tall Parents Do Not Have More Sons." Journal of Theoretical Biology 250(4): 752-53.

Epstein, Lee, Jack Knight, and Andrew D. Martin. 2003.“The Norm of Prior Judicial Experience and Its Consequences for Career Diversity on the US Supreme Court." California Law Review 91: 903-65.
Fiese, Barbara H., and Gemma Skillman. 2000. "Gender Differences in Family Stories: Moderating Influence of Parent Gender Role and Child Gender." Sex Roles 43(5-6): 267-83.

Freedman, Deborah S., Ronald Freedman, and Pascal K. Whelpton.1960. "Size of Family and Preference for Children of Each Sex.” American Journal of Sociology 66(2): 141-46.

Garrett, Major. 2009. Obama Pushes for Empathetic Supreme Court Justices." Fox News. http://www. foxnews.com/politics/2009/05/01/obama-pushesempathetic-supreme-court-justices

Gelman, Andrew, and David Weakliem. 2009. "Of Beauty, Sex and Power: Too Little Attention Has Been Paid tothe Statistical Challenges in Estimating Small Effects." American Scientist 97(4): 310-16.

Gerson, Kathleen. 1993. No Man's Land: Men's Changing Commitments to Family and new Work. New York: Basic Books.

Gottschall, Jon. 1983. “Carter's Judicial Appointments: The Influence of Affirmative Action and Merit Selection on Voting on the US Courts of Appeals." Judicature 67: 165-173.

Greenhouse, Linda. 2003. Evolving Opinions: Heartfelt Words from the Rehnquist Court." New York Times. http://www. nytimes.com/2003/07/06/weekinreview/ideas-trendsevolving-opinions-heartfelt-words-from-the-rehnquistcourt.html.

Greenhouse, Linda. 2006. Becoming Justice Blackmun: Harry Blackmun's Supreme Court Journey. New York: Macmillan.

Healy, Andrew, and Neil Malhotra. 2013. "Childhood Socialization and Political Attitudes: Evidence from a Natural Experiment." Journal of Politics 75(4): 1-34.

Howard, Robert M., and Jeffrey A. Segal. 2002. "An Original Look at Originalism." Law and Society Review 36(1): 113138.

Iacus, Stefano M., Gary King, and Giuseppe Porro. 2011. "Multivariate Matching Methods That Are Monotonic Imbalance Bounding." Journal of the American Statistical Association 106(493): 345-61.

Just, Richard. 2009. “The Empathy War.” The New Republic. http://www.tnr.com/blog/the-plank/the-empathy-war.

Kanazawa, Satoshi. 2005. "Big and Tall Parents Have More Sons: Further Generalizations of the Trivers-Willard Hypothesis." Journal of Theoretical Biology 235(4): 583-90.

Kanazawa, Satoshi. 2006. "Violent Men Have More Sons: Further Evidence for the Generalized Trivers-Willard Hypothesis.” Journal of Theoretical Biology 239(4): 450-59.

Kanazawa, Satoshi. 2007. "Beautiful Parents Have More Daughters: A Further Implication of the Generalized TriversWillard Hypothesis." Journal of Theoretical Biology 244(1): 133-40.

Kanazawa, Satoshi. 2008. "Battered Women Have More Sons: A Possible Evolutionary Reason Why Some Battered Women Stay.” Journal of Evolutionary Psychology 6(2): 129-39.

Kane, Emily W., and Laura Sanchez. 1994. "Family Status and Criticism of Gender Inequality at Home and at Work.” Social Forces 72(4): 1079-1102.

Kastellec, Jonathan P. 2013. "Racial Diversity and Judicial Influence on Appellate Courts." American Journal of Political Science 57(1): 167-83. 
Kuersten, Ashlyn K, and Susan B. Haire. 2007. "Update to the Courts of Appeals Data." Western Michigan University. http://www.wmich.edu/nsf-coa/.

Lithwick, Dahlia, and Sonja West. 2010. “The Unsung Empathy of Justice Stevens: Justice John Paul Stevens Is the Model for Why Empathy Matters." Slate Magazine: http:// www.slate.com/articles/news_and_politics/jurisprudence/ 2010/04/the_unsung_empathy_of_justice_stevens.html

Lundberg, Shelly, and Elaina Rose. 2002. "The Effects of Sons and Daughters on Men's Labor Supply and Wages." Review of Economics and Statistics 84(2): 251-68.

Martinez, Gladys, Kimberly Daniels, and Anjani Chandra. 2012. "Fertility of Men and Women Aged 15-44 Years in the United States: National Survey of Family Growth, 2006-2010." National Health Statistics Reports (51): 1-29.

Massie, Tajuana, Susan W. Johnson, and Sara Margaret Gubala. 2002. "The Impact of Gender and Race in the Decisions of Judges on the United States Courts of Appeals." Paper presented at the Annual Meeting of the Midwest Political Science Association.

Novak, Viveca. 2003. "Justice Rehnquist, Secret Feminist?" TIME Magazine: http://content.time.com/ time/magazine/article/0,9171,1005003,00.html.

Obama, Barack. 2009. The President's Remarks on Justice Souter." http://www.whitehouse.gov/blog/09/05/01/ThePresidents-Remarks-on-Justice-Souter.

Oswald, Andrew J., and Nattavudh Powdthavee. 2010. "Daughters and Left-Wing Voting." The Review of Economics and Statistics 92(2): 213-27.

Peresie, Jennifer L. 2005. "Female Judges Matter: Gender and Collegial Decisionmaking in the Federal Appellate Courts." Yale Law Journal 114(7): 1759-1892.

Pollard, Michael S., and S. Philip Morgan. 2002. "Emerging Parental Gender Indifference? Sex Composition of Children and the Third Birth." American Sociological Review 67(4): 600-613.

Raley, Sara, and Suzanne Bianchi. 2006. "Sons, Daughters, and Family Processes: Does Gender of Children Matter?” Annual Review of Sociology 32: 401-21.

Reingold, Beth, and Heather Foust. 1998. "Exploring the Determinants of Feminist Consciousness in the United States." Women and Politics 19: 19-48.

Rohde, David W., and Harold J. Spaeth. 1976. Supreme Court Decision Making. San Francisco, CA: W. H. Freeman.

Scherer, Nancy. 2004. "Blacks on the Bench." Political Science Quarterly 119(4): 655-75.

Schubert, Glendon A. 1974. The Judicial Mind Revisited: Psychometric Analysis of Supreme Court Ideology. New York: Oxford University Press.

Segal, Jeffrey A., and Harold J. Spaeth. 2002. The Supreme Court and the Attitudinal Model Revisited. Cambridge: Cambridge University Press.
Shafer, Emily F., and Neil Malhotra. 2011. "The Effect of a Child's Sex on Support for Traditional Gender Roles." Social Forces 90(1): 209-22.

Sidorowicz, Laura S., and G. Sparks Lunney. 1980. “Baby X Revisited." Sex Roles 6(1): 67-73.

Sisk, Gregory C., Michael Heise, and Andrew P. Morriss. 1998. "Charting the Influences on the Judicial Mind: An Empirical Study of Judicial Reasoning." New York University Law Review 73(5): 1377-1500.

Sloane, Douglas M., and Che-Fu Lee. 1983. "Sex of Previous Children and Intentions for Further Births in the United States, 1965-1976." Demography 20(3): 353-67.

Sunstein, Cass R., David Schkade, Lisa Michelle Ellman, and Andres Sawicki. 2006. Are Judges Political? An Empirical Analysis of the Federal Judiciary. Washington, DC: Brookings Institution Press.

Toobin, Jeffrey. 2007. The Nine: Inside the Secret World of the Supreme Court. New York: Anchor Books.

Warner, Rebecca L. 1991. "Does the Sex of Your Children Matter? Support for Feminism among Women and Men in the United States and Canada." Journal of Marriage and the Family 53(4): 1051-56.

Warner, Rebecca L., and Brent S. Steel. 1999. "Child Rearing as a Mechanism for Social Change: The Relationship of Child Gender to Parents' Commitment to Gender Equity." Gender and Society 13(4): 503-17.

Washington, Ebonya. 2008. "Female Socialization: How Daughters Affect Their Legislator Fathers' Voting on Women's Issues." American Economic Review 98(1): 31132.

Yamaguchi, Kazou, and Linda R. Ferguson. 1995. "The Stopping and Spacing of Childbirths and Their BirthHistory Predictors: Rational-Choice Theory and EventHistory Analysis." American Sociological Review 60(2): 27298.

Zuckerman, Alan S., Josip Dasović, and Jennifer Fitzgerald. 2007. Partisan Families: The Social Logic of Bounded Partisanship in Germany and Britain. New York: Cambridge University Press.

Zuk, Gary, Deborah J. Barrow, and Gerard Gryski. 2009. Multi-User Database on the Attributes of United States Appeals Court Judges, 1801-2000." Interuniversity Consortium for Political and Social Research. http://www.icpsr.umich.edu/icpsrweb/ICPSR/studies/ 6796.

\section{Supporting Information}

Additional Supporting Information may be found in the online version of this article at the publisher's website: 